\title{
LITERATURA Y FILOSOFÍA EN EL PENSAMIENTO HISPANO ¿tragicomedia de Celestina o tragedia de Pleberio?
}

\author{
Fernando Miguel Pérez Herranz \\ Universidad de Alicante
}

\section{El ensayo y la filosofía}

El género ensayístico, en tanto que genuino lenguaje de la filosofía es, en el mal sentido de la palabra, un tópico que se ha impuesto, aunque sea desmentido por los textos cosmológicos de los presocráticos, los diálogos de Platón, las epístolas de Séneca, la hipotiposis de Pirrón o el poema de Lucrecio. La discusión habitual acerca del ensayo/sistema es insuficiente. El asunto no sería grave, si no fuera porque, al omitir la relación Filosofía-pensamiento filosófico/Literatura (entendida esta última en sentido unilateralmente artístico o no), puede quedar eliminada de un plumazo toda la filosofía que se ha realizado en el mundo hispánico a lo largo de siglos. Es obligado rememorar a Miguel de Unamuno cuando nos enseña que el pensamiento filosófico español se encuentra diluido en la literatura, en la acción o en la mística1. La filosofía, esto es: la ontología, la epistemología y la ética, se encuentra disuelta y articulada en los diálogos, en el teatro, en la novela, en la poesía o en la crónica de los pensadores hispanos,

${ }^{1}$ «Pues la filosofía española está líquida y difusa en nuestra literatura, en nuestra vida, en nuestra acción, en nuestra mística, sobre todo, y no en sistemas filosóficos [...]. Las coplas de Jorge Manrique, el Romancero, el Quijote, La vida es sueño, la Subida al Monte Carmelo, implican una intuición del mundo y un concepto de la vida Weltanschaung und Labensansicht...» (M. de Unamuno, El sentimiento trágico de la vida, Alianza, Madrid, 1986, pág. 279). 
al menos entre los siglos XI al XVII. Así, desde la ontoteología providencialista hebrea y cristiana hasta la ontología tridentina y antiatomista, fundamentada en los misterios de la Trinidad y de la Eucaristía, pasando por la ontología de las naturas de Alfonso X; desde la epistemología basada en la verdad de las Sagradas Escrituras hasta la epistemología inquisitorial que suavizó la superstición histérica de las brujas, pasando por el escepticismo materialista de los médicos hispanos; desde la ética humanista que traduce las obras de Aristóteles o Cicerón hasta la configuración del derecho subjetivo de Fernando Vázquez de Menchaca, pasando por las éticas orientadas hacia la interioridad humana que se difundieron por las literaturas alumbrada y mística, o las éticas hedonistas, escép ticas y materialistas orientadas hacia la exterioridad del cuerpo, y que se espar cieron por la literatura picaresca y la de burlas. Una filosofía que, en la tradición peninsular, no iba por la vía latina de la filosofía pura (los clérigos apenas si sabían latín), sino por la vía averroísta, semita y popular, dicha en lingua tholetana, divorciada del latín para desposarse en España con el vernáculo durante los siglos venideros ${ }^{2}$. ¿Puede toda esta obra arrojarse, sin más razones que los prejuicios ilustrados, a la Edad Oscura o la Edad de las Tinieblas, sinónimos usuales de la Edad Media hispana? Ya el propio término, Edad Media, es nombre impropio, si no absurdo, para caracterizar una época tan rica como creativa. Los humanistas a partir del obispo Giovanni Andrea di Bussi (1417-1475) adoptaron este término, y otros similares, para designar el tiempo que había olvidado las letras latinas. Pero en la Hispania de estos siglos «oscuros y tenebrosos» nunca se perdió el contacto ni con las letras ni con las ciencias: las traducciones de unas lenguas a otras —árabe, griego, hebreo, latín, castellano-; las polémicas referidas a los Textos Sagrados; la literatura arábiga, que, junto a la rabínica, influyó decisivamente en el restablecimiento tanto de las Buenas Letras (Poesía, Elocuencia, Historia o Filología) como, sobre todo, de las Ciencias (Naturales y Eclesiásticas) y de las Artes (papel, números, pólvora o brújula) en toda Europa a través de los reinos hispanos, como supo ver ya a finales del siglo XVIII el sabio jesuita expulso Juan Andrés ${ }^{3}$. Por todo ello, en otro lugar he propuesto calificar positivamente a esta época como 'Edad del Libro'4.

\section{La «experiencia conversa»}

En nuestra época post-ilustrada, post-moderna y de la post-verdad, es muy difícil, seguramente imposible, mostrar la potencia intelectual de la Hispania

2 F. Márquez Villanueva, «El caso del averroísmo popular español (hacia La Celestina)», en J. L. Canet, Cinco siglos de 'Celestina': aportaciones interpretativas, Universitat de València, 1997, págs. 121-134.

${ }^{3}$ Juan Andrés, Origen, progresos y estado actual de toda la literatura (edición de J. García, S. Navarro y C. Valcárcel, dirigida por P. Aullón de Haro), Verbum, Madrid, 1997, 6 vols.

${ }^{4}$ Cf. F. M. Pérez Herranz, Lindos y tornadizos. El pensamiento filosófico hispano (siglos $X V$-XVII), Verbum, Madrid, 2016. 
de los siglos XIV al XVII, más allá del ámbito de los especialistas. La Filosofía se ha ido asociando a unos cuantos textos «sacralizados» que leen algunos profesores encerrados en las bibliotecas o dictan en las aulas. Pero la Filosofía verdadera está asociada a experiencias humanas decisivas, irreversibles y universalizables. El pensamiento de la época que nos ocupa es inseparable de una experiencia única, la experiencia conversa o marrana ${ }^{5}$, antes y después del decreto de conversión-expulsión de 1492. Antes: desde las disputas entre judíos y cristianos hasta el humanismo hispano de Alfonso de la Torre, Alfonso de Madrigal, Ramón Sibiuda o Alonso de Cartagena, pasando por el proyecto de cristianización de Benedicto XIII desde Avignon, con la fundación del Estudio de Valencia (1411, universidad en 1450) y los estatutos de la Universidad de Salamanca (1422). Después: desde el humanismo de Luis Vives y León Hebreo, fuera del reino, hasta las vías corporeístas de La Celestina o de Gómez Pereira y la vía interiorista de alumbrados y místicos, pasando por las traducciones de los textos bíblicos: la Políglota, el Cantar de los Cantares de fray Luis de León; sin olvidar la definición del sujeto del imperio que trazan Fernán Pérez de Oliva, la Escuela de Salamanca: Luis de Molina, Francisco de Vitoria o Francisco Suárez, fuente de las metafísicas francesa y alemana del siglo XVII, o Ignacio de Loyola y su Compañía de Jesús. Una experiencia conversa que llega, por contraposición, hasta la ética de Francisco de Quevedo, la fenomenología de Pedro Calderón de la Barca o la ontología eucarística de Baltasar Gracián. Y, entreveradas por todo este pensamiento, dos obras singulares que muestran los límites alcanzados por aquella experiencia: La Celestina, que expresa la imposibilidad del sujeto puro (cristiano, el que triunfaría con el cogito cartesiano, que elimina gratuitamente todos los «ropajes» de la naturaleza y que condujo al pensamiento europeo hasta el nihilismo, como advirtió genialmente Nietzsche); y la espectacular invención de la novela por Miguel de Cervantes, Don Quijote de la Mancha, habrá de sustituir al Libro, desterrado ya como lectura cotidiana y fuente de los criterios de verdad, de moralidad y de la propia ontología del mundo que el cristianismo había propiciado. Me centraré en esta ocasión en La Celestina ${ }^{6}$.

${ }^{5}$ Utilizo el término converso para referirme a los convertidos al cristianismo, sinceros o indiferentes; y marrano para los criptojudíos a quienes se les ha cortado todo lazo con su antigua religión. Converso es un término más genérico que marrano; significa que, aun cuando un individuo haya cambiado de religión, no puede pertenecer a ella, porque lo prioritario es la «sangre», la contaminación de la «raza» a la que pertenece, independientemente de su intencionalidad, de si es o no judaizante. En este sentido de falso converso, el término se encuentra en un poema de Brito del siglo XV. Véase, D. Gonzalo Maeso, «Sobre la etimología de la voz marrano (criptojudío)», Sefarad, 15, 1955, págs. 373-385.

${ }^{6}$ F. de Rojas, La Celestina (ed. de B. M. Damiani), Cátedra, Madrid, 1975. Cito el auto y la página de esta edición. 


\section{La Celestina, modelo para la filosofía}

Hay muchas maneras de leer La Celestina y es muy probable que todas ellas estén recogidas en la abundantísima bibliografía al respecto y poco pueda decirse que no se haya dicho de esta obra universalmente reconocida. Quizá pueda intentarse una lectura fenomenológica o deconstruccionista, capaz de poner en suspenso (epojé) todas las capas hermenéuticas que se han ido asentando sobre ella. O quizá pueda tantearse como una obra de filosofía escrita en el contexto de los programas político-religiosos de una Europa que pretende alcanzar la Universitas Christiana : tal es mi propuesta. Partiré, en todo caso, de tesis aceptadas por filólogos y críticos literarios. El Auto I se origina como un ejercicio de lógica: razonamientos y máximas, en el ambiente de confrontación entre las diversas escuelas en la universidad de Salamanca ${ }^{8}$, una vez que en la recién fundada universidad de Alcalá el cardenal Cisneros ha exigido que en la Facultad de Teología haya cátedra de cada una de las tres vías ontológicas: tomista, escotista y nominalista; por eso se discute su autoría: el bachiller Fernando de Rojas o quizá gente más principal —nobles, eclesiásticos o profesores interesados en reformar la enseñanza y con recursos para imprimir la obra9 - La Celestina se publica tras el decreto de conversión-expulsión (la primera edición conocida es de 1499) y está vinculada a los conversos $^{10}$. Se escribe en castellano, el vernáculo inventado por Alfonso X como lengua de cultura en el cruce del latín con el hebreo y el árabe. En el prólogo de la obra, se hace explícita mención del humanismo italiano en la figura de Petrarca, pero también de los exempla morales de tradición hebrea; en la carta «El autor a un su amigo», éste conecta con la tradición de los «claros ingenios de doctos varones castellanos», alejada de las herrerías de Milán. Juan de Mena y Rodrigo de Cota son sus referencias explícitas; y el Libro de buen amor y el Corbacho, las implícitas; entronca con la tradición española alfonsí de las parábolas o exempla morales, de sententiae y de haggadot rabínicas, que cristalizó en El conde Lucanor de don Juan Manuel. A La Celestina se la

${ }^{7}$ La idea de una Universitas Christiana es fundamentalmente erasmista. Erasmo de Rotterdam defiende una Europa unida sobre la base de la religión cristiana, capaz de difundir el cristianismo más allá de sus fronteras. Su Instituto principis christiani (1516) se la dedicó a Carlos V, como líder espiritual y no como agresor. La idea fue desarrollada por intelectuales españoles: Pedro Ruiz de la Mota, Hugo de Moncada o Alfonso de Valdés. María Elvira Roca Barea, con razón, afirma que el protestantismo surgió, precisamente, para que este proyecto no triunfara. Véase su argumentación en Imperiofobia y Leyenda Negra, Siruela, Madrid, 2016.

${ }_{8}^{8}$ Por las anotaciones al margen de un ejemplar encontrado en Zaragoza de 1507. Cf. N. Baranda, «Leyendo 'fontezicas de filosophía'. Marginalia a un ejemplar de la Tragicomedia de Calisto y Melibea (Zaragoza, 1507)», en J. C. Conde (ed.), Actas del Simposio Internacional 1502-2002: Five years of Fernando de Rojas 'Tragicomedia de Calisto y Melibea', Hispanic Seminary of Medieval Studies, Nueva York, 2007, págs. 269-309.

${ }^{9}$ Es la tesis defendida por José Luis Canet, «Introducción» a su edición crítica de Comedia de Calisto y Melibea, Universitat de València, 2011.

${ }^{10}$ S. Gilman, La España de Fernando de Rojas, Taurus, Madrid, 1978. 
ha llamado «floresta de filósofos»"11 y muchos estudiosos han perseguido las fuentes utilizadas por el autor: Aristóteles, Séneca, la Biblia, Petrarca y textos jurídicos ${ }^{12}$; sorprende, en cualquier caso, que las sentencias puestas en boca de los personajes no sean populares, como correspondería a su estamento social, sino que remitan a textos clásicos ${ }^{13}$ y bíblicos ${ }^{14}$, y que se acompañen de una cantidad enorme de juegos de palabras, oxímoron, sorites... Escuchemos a Sempronio, Pármeno y Celestina hablar por boca de Aristóteles ${ }^{15}$ :

SEMPRONIO - Porque sin los bienes de fuera, de los cuales la fortuna es señora, a ninguno acaece en esta vida ser bienaventurado; y más, a constelación de todos eres amado (I, 64). Sine rebus exterioribus quorum fortuna domina est non contingit felicem esse (fol. 158r; AA, XIII, 1; Aristóteles, Magna moralia 1206b33-34).

PÁRMENO - No curo de lo que dices, porque en los bienes mejor es el acto que la potencia y en los males mejor la potencia que el acto. Así que mejor es ser santo, que poderlo ser. Y mejor es poder ser doliente que ser enfermo por acto y, por tanto, es mejor tener la potencia en el mal que el acto (I, 83). In bonis actus melior est potentia sed in malis melior est potentia actu quod patet $<$ quia $>$ actu esse sanum melius est quam posse fieri sanum sed pose fieri infirmun melius quam actu esse infirmum (fol. 139v; AA, I, 230-231; Aristóteles, Metafisica 1051a13-17).

CELESTINA - Y demás de esto, ¿quién es, que tenga bienes en la república, que escoja vivir sin amigos? [...] que cuanto mayor es la fortuna, tanto es menos segura. Y, por tanto, en los infortunios el remedio es a los amigos. ¿Y a dónde puedes ganar mejor este deudo, que donde las tres maneras de amistad concurren, conviene a saber, por bien e provecho e deleite? (I, 87). Nullus eligeret vivere sine amicis habens reliqua bona omnia. Quanto maior est fortuna tanto minus est secura [...] In infortunius refugium ad amicos [...] Triplex est amicicia scilicet propter utile bonum delectabile et honestum (fol. 156v; AA, XII, 143; Aristóteles, Ética a Nicómaco 1156a7-14).

${ }^{11}$ P. E. Russel, «Discordia universal: La Celestina como 'floresta de filósofos'», Ínsula, 497, 1988, págs. 1-3.

${ }_{12}$ F. Castro Guisasola, A. D. Deyermond, I. A. Corfis, L. Forthergill-Payne, Í Ruiz Arzálluz, etc.

${ }^{13}$ Por ejemplo, Í. Ruiz Arzálluz, «El mundo intelectual del 'antiguo autor': las Auctoritates Aristotelis en La Celestina primitiva», Boletín de la Real Academia Española, LXXVI, 1996, págs. 265-284.

${ }^{14}$ Cf. E. Castro, «La Biblia y el universo dramático medieval», en M. I. Toro, La Biblia en la literatura española, I/1, Trotta, Madrid, 2008, pág. 199.

${ }_{15}$ Se cita el capítulo y página del texto de La Celestina; el texto correspondiente del repertorio Auctoritates Aristotelis, según el estudio de Íñigo Ruiz Arzálluz; y la referencia de la obra de Aristóteles. 
Y para terminar por algún lado, el tema es bastante simple y conecta con otras obras clásicas y de la comedia humanística ${ }^{16}$ : el amor frustrado de dos jóvenes enamorados.

\section{La pregunta filosófica}

En una primera lectura, siempre ansiosa por ver cómo se desenvuelven los sucesos y adónde conducen, es natural que el lector quede perplejo y aun sobrecogido: todos los personajes fracasan; ninguno sale airoso del papel que representa: ni los enamorados Calisto y Melibea; ni sus padres Pleberio y Alisa; ni los criados Sempronio y Pármeno con sus parejas, Areúsa y Elicia; ni el rufián Centurio. Ese estado de inestabilidad emocional obliga a una nueva lectura, ahora ya de cariz filosófico, sobre cuál sea la estructura del mundo que acoge a esos personajes, sobre los criterios de verdad que emplean y sobre la valoración de sus acciones.

El método filosófico nos compromete con un doble movimiento: primero de diairésis (división) o regressus hacia las Ideas que conforman las condiciones de posibilidad del propio discurso: unas Ideas que, en el límite, pueden formar un sistema; y, después, de sinagogué (unión) o progressus o vuelta al mundo del que partimos, que quedará comprendido, si el recorrido ha sido eficiente - pues las Ideas halladas pueden quedar desconectadas del propio mundo de partida-, en términos de las mismas Ideas alcanzadas ${ }^{17}$. Sirva como ejemplos, el clásico sistema filosófico de Hegel; o la imposibilidad del progressus hacia el mundo de partida de la teología apofática (apofasko, «negar») de Dionisio Pseudo-Areopagita (c. siglo VI), a partir de un concepto de un Dios al que se niega cualquier atributo obtenido del mundo sensible e inteligible. Volvamos, entonces, al principio.

Ahora podrá calibrarse mejor la desconcertante negación directa del Libro Sagrado en los mismos inicios de La Celestina. Calisto se enfrenta al dios creador sin mediación ni recato:

¿Yo? Melibeo soy, y a Melibea adoro, y en Melibea creo, y a Melibea amo (I, 59).

Todas las facultades del ser humano que es Calisto (voluntad, entendimiento y memoria) se someten a su dios, que es Melibea, una mujer, con la que se fusiona y disuelve. Y ya nos asalta el primer dilema: esta Melibea ¿es, como marca la tradición griega, la Pandora que ha despertado todos los males? ¿O quizá es una mujer que junto al varón conforman la estructura analógica por

${ }^{16}$ M. R. Lida de Malkiel, La originalidad artística de 'La Celestina', EudEBA, Buenos Aires, 1962.

${ }^{17}$ El método formalizado por Platón en Fedro, 264e-266c. 
medio de la cual se conoce el mundo, al modo de la Amada del Cantar de los Cantares que traducirá exquisitamente Fray Luis de León unos años después?

El dilema es vibrante, porque más tarde Calisto y Melibea, o Melibea y Calisto, se definen uno en relación al otro. Pero la analogía es un método demasiado abierto y debe ser cerrado con criterios causales, no metafóricos. ¿Cuál es el criterio de verdad que emplean los personajes? En La Celestina no se encuentran conocimientos claros y distintos, no se sabe si vivimos engañados o instalados en la verdad, porque todo lo que hay son acciones: «A las obras creo; que las palabras, de balde las venden dondequiera» (VII, 164) enseña Celestina. La obra va narrando las peripecias de estos personajes con un fin, aparentemente, moralizante, para que los jóvenes aprendan en cabeza ajena los peligros que surgen, en esos primeros pasos que conducen al amor, de los engaños de las alcahuetas y de la avaricia de los criados. Mas, sobre todo, del peligro que puede provocar saltarse la distancia social, pues es muy arriesgado, repararán jóvenes y adultos, mezclar dos linajes que no se corresponden ${ }^{18}$ : el lindo caballero Calisto y la tornadiza hijosdalga Melibea, puesta en entredicho por Elicia, que se enfrenta a Sempronio por llamar «graciosa y gentil»» a Melibea: «Elicia.— Da asco de oírte llamar a aquella gentil». Sempronio tercia: Calisto y Melibea son nacidos por linaje; y Areúsa remite, irónicamente, justo a la unidad de los seres humanos: «Areúsa.- Las obras hacen linaje, que al fin todos somos hijos de Adán y Eva. Procure de ser cada uno bueno por sí, y no vaya a buscar en la nobleza de sus pasados virtud» (IX, 185-187). En la primera lectura ya habíamos advertido cómo se frustra la relación entre los dos linajes de Calisto y Melibea y cómo esa frustración arrastra al resto de personajes. Recordemos: Celestina, Sempronio y Pármeno mueren; Areúsa y Elicia buscan venganza; la cobardía de Centurio apela al linaje en su oficio de rufián (XVIII, 274); y al final de la obra Pleberio se muestra desesperado, en el límite entre la vida y la muerte: «¿Por qué te mostraste tan cruel con tu viejo padre? ¿Por qué me dejaste cuando yo te había de dejar? ¿Por qué me dejaste penado?» (XXI, 299). Pero estas acciones van mucho más allá del ejemplo moral. En esta segunda lectura, siguiendo la diaresis filosófica, podemos reflexionar en el absoluto fracaso de la comunicación que se da en las relaciones de los enamorados, en las relaciones de amos y siervos, y en las relaciones de los siervos entre sí. ¿Cómo no sospechar de la Inquisición estatal y del decreto de conversión-expulsión como fractura comunicacional entre los súbditos del reino? Ningún hilo de unión caritativa se establece entre ellos, ese engarce de unión que es la clave de la vida cristiana, la charitas, el vínculo entre los hombres a través de Cristo, y que fray Luis de León sabrá cantar de manera fascinante:

Porque su amor, digo el que los suyos le tienen, nos provee a todos y nos rodea de amigos que, olvidados por nosotros, nos buscan, y no conocidos,

${ }^{18}$ Si hubiese correspondencia, naturalmente, bastaría con que Calisto pidiera a Pleberio la mano de su hija. 
nos conocen, y ofendidos, nos dessean y nos procuran el bien, porque su desseo es satisfacer en todo a su Amado, que es el Padre de todos ${ }^{19}$.

Menéndez Pelayo lo advierte con extrañeza: «Viven dentro de una sociedad cristiana, practican la devoción exterior, pero hablan y proceden como gentiles, sin noción del pecado ni del remordimiento». Aquí sí hay oscuridad y tinieblas; es la falta de luminosidad de la noche, junto con otras causas insignificantes, lo que provoca la caída al vacío de Calisto. Con una frialdad que nos sobrecoge, lo narra la enamorada Melibea:

Como las paredes eran altas, la noche oscura, la escala delgada, los sirvientes que traía no diestros en aquel género de servicio y él bajaba presuroso a ver un ruido que con sus criados sonaba en la calle, con el gran ímpetu que llevaba, no vio bien los pasos, puso el pie en vacío y cayó (XX, 291).

Y, a partir de esa caída y muerte, se liberan todas las demás catástrofes, incluido el suicidio de Melibea: «Su muerte convida a la mía, convídame y fuerza que sea presto, sin dilación, muéstrame que ha de ser despeñada por seguirle en todo» (XX, 292). Ahora bien, si no es posible llevar a buen término la comunicación en una sociedad cualquiera, no puede realizarse la charitas cristiana. Fernando de Rojas o el grupo de profesores de Salamanca al que hacíamos referencia han dado con la clave de la sociedad pretendidamente cristiana: si no hay relaciones a través de la caridad, todo es arbitrariedad: tanto del poder como de las cosas cotidianas que suceden. La Celestina refleja esa política del dudosamente católico (kathólou) Fernando, cuya pura voluntad de poder no tiene en cuenta los intereses de los súbditos: se niega a pactar con los judíos, algo que sí habían hecho sus antecesores; los expulsa, a la vez que somete a los conversos y pone en guardia a los cristianos, que han de apelar, histéricos, al linaje, y no al argumento. Se acabaron las disputas entre la Sinagoga y la Iglesia, se anularon todos los intermediarios y quedan los hombres desamparados en busca de la supervivencia. Fernando el Católico se ha incorporado al juego de consolidar el poder de sus reinos y de volcarse hacia la toma de Jerusalén, en el que participan Maximiliano de Habsburgo (1459-1519), casado con María de Borgoña, hija de Carlos el Temerario, sucesor de Felipe III el Bueno, fundador de la Orden del Toisón de Oro, en la que no caben los herejes; Luis XI (1461-1483) y su sucesor Carlos VIII (1483-1498), ávido lector de libros de caballerías; Enrique VII de Inglaterra (1485-1509); o Juan II (1481-1495) de Portugal y su hijo Manuel I el Afortunado (1495-1521), que sospechaba de sí mismo ser el «afortunado» elegido que inauguraría la postrera edad del mundo cristianizado. Tras el fracaso de los Anjou y de los reyes aragoneses, les llega el turno a Fernando e Isabel, los monarcas del

${ }^{19}$ Luis de León, Los nombres de Cristo, libro III, «Amado», en Obras completas castellanas, BAC, Madrid, 1944, pág. 752. 
poderoso reino de Castilla y Aragón, y en ellos se cumplirían los planes y programas de los distintos papas para extender a todo el mundo la buena nueva del Evangelio de Cristo, de quien son vicarios en la Tierra. Antes de que se consoliden los prejuicios de las historias nacionales, la historia de España no es sino un momento más de la historia de Europa, de sus planes y de sus programas, vinculados a la Idea difusa de una Cristiandad proselitista: «Id por todo el mundo y predicad el Evangelio a toda criatura» (Marcos 16: 15).

La Celestina está mostrando a los estudiantes universitarios, al público cultivado de la época, la falta de comunicación entre los hombres, y aun la imposibilidad misma de esa Universitas Christiana. Y si esto es así, únicamente queda la ontología del individuo: o por la vía del cuerpo o por la vía del alma. Los médicos hispanos seguirán el primer camino y conectarán con la tradición saducea, para la que no hay otro mundo, sino el que se contiene entre el nacimiento y la muerte: «Mas guardaos de presumir/ lo que tienen los maluados, / que non ay en el bivir/ sino nascer e morir/ como salvajes venados» versifica Diego Arias. Otros, alumbrados y místicos, cercanos a los movimientos reformistas franciscanos, aspiran a la perfección espiritual y dejan un modelo de vida tras de sí. Como advierte Frémaux-Crouzet, la fuerza de la Contrarreforma española no se explicaría únicamente por la beligerancia del aparato inquisitorial del que se rodeó para vigilar el dogma, «sino por haber conservado paralelamente a éste las ansias de espiritualidad reformadora amansadas en su propia historia ${ }^{20}$. Muchos de aquellos hombres - Pedro Ruiz de Alcaraz, Gaspar de Bedoya, Juan de Cazalla, los hermanos Juan y Francisco de Vergara, Luis de Beteta, Miguel de Eguía...- y mujeres - María de Cazalla, Isabel de Tovar, Petronila del Castillo... - se verán compelidos a oficiar de «teólogos» improvisados, a bucear en los misterios de la nueva religión que han aceptado y que inevitablemente comparan con la antigua religión que han abandonado; y esta situación los invita a vivir en una tensión e inquietud religiosa que los cristianos viejos no poseen, porque les basta con seguir las ceremonias y las costumbres $^{21}$. Lo que hoy nos puede conmover de aquella singularidad histórica es que no quedase en el olvido, sino narrada y conceptualizada, a la vez, por una obra teatralizada. Lo que hoy nos puede sorprender y fascinar es que $L a$ Celestina diera cuenta de ese momento histórico de ruptura que se produce al socaire del nombramiento de inquisidores estatales (1480) y del decreto de conversión-expulsión (1492) por Fernando e Isabel, y que constituyeron un «golpe de estado» definitivo contra el legado alfons $i^{22}$, contra las ciudades conversas, mudéjares y mixtas de cristianos nuevos y viejos, judíos y muladíes, despreciadas por la Europa cristiana.

${ }^{20}$ A. Frémaux-Crouzet, Concierto del alma. Cábala y utopía en Fray Luis de León, Universidad Autónoma de Madrid, 2010, pág. 94.

${ }^{21}$ Cf. S. Pastore, Una herejía española. Conversos, alumbrados e inquisición (1449-1559), Marcial Pons, Zaragoza, 2010.

${ }^{22}$ F. Márquez Villanueva, La cultura alfonsí, Mapfre, Madrid, 1994. 
Porque toda esa enorme conflictividad no puede ser expresada dentro del rígido marco lógico de la Escolástica. Es más flexible hacerlo desde la acción misma. En La Celestina son las acciones, no los conceptos, las que van construyendo la ontología, de modo que, al desaparecer los personajes, desaparece con ellos el sentido. No hay mediación en ese mundo azaroso en el que cualquier detalle nimio puede provocar la catástrofe: una discusión familiar, una palabra de más en la conversación cotidiana, una ironía o una broma en el mercado. La experiencia conversa enseña a los hombres que el mundo no es un orden providencial, sino solamente un «laberinto de errores» (XXI, 295). El mundo se configura extensionalmente, sin intencionalidad alguna: sucesos causales, encadenamientos mecánicos: «Del mundo me quejo —concluye Pleberio en un espléndido sorites-, porque en sí me crió; porque no me dando vida, no engendrara en él a Melibea; no nacida, no amara; no amando, cesara mi quejosa y desconsolada postrimería» (XXI, 299). Un mundo que se vive, se sufre y se disfruta al margen de las mediaciones políticas o religiosas. El límite de las acciones de los personajes es la ciudad misma, y todas sus mediaciones son sociales, y su símbolo es la propia Celestina. Un antitético segundo dilema nos sale al paso: ¿Fracasan los personajes porque fracasan los mediadores religiosos y políticos? ¿O fracasan los mediadores porque fracasa la propia naturaleza humana? Si es posible darle una salida al dilema, habrá de configurarse alguna idea sobre el Sujeto que lo sostiene.

\section{5. ¿Qué tipo de Sujeto puede soportar esta realidad?}

De manera que este estado de cosas obliga a buscar algún fundamento en el que afianzar el sentido de la vida. ¿Dónde encontrarlo? Si se descartan el Orden neoaristotélico cristianizado de la escolástica o el Amor cósmico platonizante de un León Hebreo, ¿qué queda? ¿Las puras pasiones: la codicia, la sed de venganza? ¿El mal? Una vez más acecha el gnosticismo. ¿Cómo neutralizar todas esas desgracias, que a lo largo del siglo se harán cada vez más terribles? ¿Cómo plantarle cara a este mundo, tan inhóspito para el hombre? ¿Qué sujeto puede soportar esta realidad? Pues bien, mucho antes de que Descartes hiciera lo propio en respuesta al mundo desgarrado por las guerras para la formación de los estados-naciones (paz de Westfalia), camufladas como guerras de religión entre cristianos reformados (luteranos, calvinistas, anglicanos...) y contrarreformados, esto es, entre los cristianos mismos, en aquel siglo de experiencias sobreabundantes y de testimonios ajenos a cualquier criterio de verdad, en el que todo cabe ${ }^{23}$, La Celestina había iniciado el primer envite para construir un Sujeto que pudiera hacerse cargo de un mundo desnortado,

${ }^{23}$ «Uno de los rasgos más curiosos y más característicos de la época es esta ausencia total en el pensamiento de la categoría de lo imposible. Todo es posible, de lo que se deriva una credulidad sin límite y sin crítica» dice Alexandre Koyre (Místicos espirituales y alquimistas del siglo XVI alemán, Akal, Madrid, 1987, pág. 87). 
que abandonaba la Edad del Libro y entraba en la Edad de la Técnica y de las Naciones con una energía descomunal. Sus personajes no son reyes ni nobles ni guerreros, pero tampoco son populares, festivos o danzarines. Son hombres y mujeres que se construyen en el lenguaje, en las reacciones de unos contra otros; que luchan por sobrevivir y que desaparecen con su muerte. Podríamos decir que ni ellos ni sus obras permanecen, sino los objetos por los que se afanan: cadenas o collares de oro; ni siguen modelo ejemplar alguno, ni ellos mismos son ejemplos de nada. Es muy significativo que el propio título de la obra haya ido cambiando a lo largo de los años: unas veces se conoció como Melibea, otras como Calisto y Melibea, o, en fin, como La Celestina. El amor entre Calisto y Melibea ha de vivirse lejos del alcance de la vigilancia social, en la oscuridad de la noche. Cuando fallan los cauces comunicativos y cualquier acción puede ser sospechosa, las únicas salidas son la mentira, el engaño, la desconfianza... En ese contexto de cierre de una Europa puramente cristiana en el que fracasa la mediación de la charitas, los filósofos encontraron una manera de salvar el obstáculo que les impedía establecer un fundamento ontológico para el Hombre: narrar el mundo desde la primera persona. Primero fue Michel Montaigne (1533-1592), y luego René Descartes (1596-1650), quienes trazarán las coordenadas del Sujeto moderno ${ }^{24}$. Pero ya La Celestina había presentado los argumentos propios de un cogito, de un sujeto trascendental, que, en contrapartida del cartesiano, no es puro Pensamiento, sino puro Gozo. Veamos.

\section{6. «Gaudemus ergo sumus»}

Calisto expresa el principio del cogito, y lo formaliza como principio ontológico: «Melibeo soy» exclama. Pongámoslo en latín para darle empaque filosófico y acercarlo al famoso argumento del cogito cartesiano: «Melibeo sum». Calisto, al cambiar la apariencia del joven por la esencia de la amada, no se constituye ya en la mera existencia, sino en el goce de Melibea. La esencia de Calisto no es la Vida, de tradición hebrea; tampoco es la Gracia, dogma básico del cristianismo; ni el Pensamiento, la deriva cartesiano-kantiana. La esencia de Calisto es el Goce mismo. Traduzcámoslo a fórmula latina: «Gaudeo ergo Melibeo sum». Este principio no es pura abstracción, sino principio corpóreo, varonil, que, para ser válido, ha de ser refrendado por la mujer. Porque Melibea también se constituye como ser en el Goce: «Señor, yo soy la que gozo, yo la que gano» (XIX, 283). Melibea es sujeto-acción, no objeto-pasividad. Latinizado, habría podido decir: «Gaudeo, acquirere», si acquirere se entiende en su sentido de aumentar el crédito (Cicerón), de proporcionar dignidad (Virgilio). Solo al gozar a Calisto, Melibea se ontologiza, se llena de ser:

${ }^{24}$ Cf. M. Cruz (comp.), Tiempo de subjetividad, Paidós, Barcelona, 1996. 
Faltándome Calisto, me falta la vida, al cual, porque él de mí goce, me aplace» (XVI, 262) [...] ¿Cómo no gocé más del gozo? (XIX, 285).

Es gozando a Calisto cuando Melibea adquiere fundamento ontológico y puede abrirse a la existencia. Por simetría con el «Melibeo sum», puede convenir esta fórmula: «Calista soy/Calista sum». Si se me permite el anacronismo, de ambas fórmulas obtendríamos un principio que engloba al hombre y a la mujer, indiferenciados en el plural, pero no absorbidos por la abstracción del Pensamiento o de la Extensión: «Gaudemus ergo sumus». El Gozo, no esta o aquella pasión, es la fuente ontológica del Universo. Y esa fuente se materializa a través de los sentidos. Calisto despliega el gozo a través de la vista, los oídos, el tacto, la boca:

Trae a mi fantasía la presencia angélica de aquella imagen luciente, vuelve a mis oídos el suave son de sus palabras, aquellos desvíos sin gana, aquel «Apártate allá, señor, no llegues a mí»; aquel «No seas descortés», que con sus rubicundos labios veía sonar, aquel «No quieras mi perdición», que de rato en rato proponía, aquellos amorosos abrazos entre palabra y palabra, aquel soltarme y prenderme, aquel huir y llegarse, aquellos azucarados besos, aquella final salutación con que se me despidió. ¡Con quanta pena salió por su boca! ¡Con cuantos desperezos! ¡Con cuantas lágrimas, que parecían granos de aljófar, que sin sentir se le caían de aquellos claros y resplandecientes ojos! (XIV, 250).

Este principio ontológico del ser se extiende a la teoría del conocimiento: el goce es el criterio de verdad:

Pues él me ama, ¿con qué otra cosa le puedo pagar? [...] el amor no admite sino sólo amor por paga. En pensar en él me alegro; en verlo me gozo; en oírlo me glorifico. Haga y ordene de mí a su voluntad. Si pasar quisiere la mar, con él iré; si rodear el mundo, lléveme consigo; si venderme en tierra de enemigos, no rehuiré su querer. Déjenme mis padres gozar de él, si ellos quieren gozar de mí. No piensen en estas vanidades, ni en estos casamientos; que más vale ser buena amiga que mala casada (XVI, 261).

El Amor-Gozo es un principio más profundo que la Vida, la Gracia o el Pensamiento; se encuentra incluso más allá del mismo Dios, creador de las criaturas finitas, que no pueden hacer otra cosa sino amar-gozar. Y porque es un principio ontológico, y no un aspecto más del mundo, el Amor deja de ser un pegamento que une las cosas y, en tanto que Gozo, constituye al Sujeto humano, un Sujeto segregado del mundo, con todas sus consecuencias.

Por eso el Amor-Gozo mata, sin paradoja, a quien lo elige. Pues si «Dios mata a quien crió [...], el amor mata a quien le sigue» (XXI, 298). El nivel ontológico ha de constituirse más allá de la política, de la religión y de la ideología. 
Esta es la gran idea de la literatura española de la experiencia conversa y de sus descendientes: la desconfianza en la mediación y en la articulación político-religiosa, origen de todas las desgracias en Hispania, al menos desde 1391. Fernando de Rojas indicó el Gozo; luego los alumbrados y los místicos, la Interioridad; Francisco de Vitoria, el Ius communicationis; Miguel de Cervantes, la caridad del guerrero; Fernando Vázquez de Menchaca, el derecho subjetivo... Pero nunca el sujeto político nacional que aplasta todos los niveles de la vida, el sujeto nación que fundó el luteranismo en Alemania, el calvinismo en los Países Bajos o el anglicanismo en Inglaterra. Los tornadizos recelarán ya para siempre de la figura del monarca, que, desde Alfonso el Sabio, había garantizado la vida de los hebreos en España. Nos congratula que Menéndez Pelayo haya sido sensible a esta idea y que la intención de Rojas haya sido la de hacer abstracción de todo, excepto del Amor:

Para Rojas el amor es una deidad misteriosa y terrible, cuyo maléfico influjo emponzoña y corrompe la vida humana y venga en los hijos los pecados de los padres. Se alimenta del llanto y de la sangre de cien generaciones, trituradas entre las ruedas de su carro. No es sólo el exceso de la desesperación ni el flujo retórico, sino una convicción arraigada la que dicta las últimas palabras del venerable Pleberio, que contienen, a mi juicio, la filosofía del drama: «iOh amor, amor! [...] ¿Quién te dio tanto poder?». Y no es sólo el anciano Pleberio quien prorrumpe en tan doloridos acentos. Es el mismo Calisto, en quien las primeras caricias de Melibea no llegan a borrar el sentimiento de la muerte afrentosa de sus criados y de su propia deshonra y vilipendio... ${ }^{25}$

El mundo neoaristotélico de Tomás de Aquino (1225-1274), ordenado y conectado en todos sus niveles ha sido resquebrajado desde prácticamente el mismo día en que nació. Poco tiempo después de la Summa Theologica, Duns Escoto (1266-1308) reveló la desconexión entre Dios y sus criaturas, mucho antes de que Descartes clausurara el mundo tomista y abriera el mundo nominalista de la revolución científica ${ }^{26}$. La Celestina mostró también las consecuencias de esa desconexión, aunque desde la experiencia conversa, no cristiana, pero tampoco judía. En el Planto de Pleberio, ese mundo manifestado a escala divina (en la que, por ejemplo, está expresada la Divina Comedia de Dante) ya empezaba a ser clausurado. En el mundo regido por leyes naturales deterministas, del que Dios se ha retirado, únicamente queda el Gozo como principio ontológico del ser humano: tal es la lección de La Celestina.

En este mundo determinista no hay nada superfluo: «Que no creas que en balde fuiste criada. Que, cuando nace ella, nace él, y cuando él, ella. Ninguna cosa hay criada al mundo superflua ni que con acordada razón no proveyese

${ }_{25}$ M. Menéndez Pelayo, Orígenes de la novela. X. La Celestina, Casa Editorial Bailly-Baillière, Madrid, 1910, pág. 382.

${ }^{26}$ A. de Muralt, La apuesta de la filosofía medieval. Estudios tomistas, escotistas, ockamistas y gregorianos, Marcial Pons, Madrid, 2008. 
de ella natura» dice Celestina a Areúsa (VII, 62). La Naturaleza, inmersa en el espacio, es inconmensurable con el hombre. Es espléndido el momento en que Calisto, tras haber pasado la noche con Melibea, y en un intensísimo soliloquio, desconecta al hombre y sus circunstancias del espacio que lo engloba. Si las acciones cambian a medida de nuestras inclinaciones e intereses, el espacio, ajeno e indiferente, no cambia a medida de nuestros deseos:

No aprenden los cursos naturales a rodearse sin orden, que a todos es un igual curso, a todos un mismo espacio para muerte y vida, un limitado término a los secretos movimientos del alto firmamento celestial de los planetas, y norte de los crecimientos y mengua de la menstrua luna. Todo se rige con un freno igual, todo se mueve con igual espuela: cielo, tierra, mar, fuego, viento, calor, frío. ¿Qué me aprovecha a mí me dé doce horas el reloj de hierro, si no las ha dado el del cielo? (XIV, 250).

En un mundo hostil y extraño, un mundo de cosas en continuo batallar, en el que la Fortuna es pasajera, La Celestina presenta una ontología heracliteana, tan cara a los conversos. Álvarez Gato exclama: «Todo es peligro e batalla quanto ay sobre la tierra»; y Mateo Alemán, otro converso, escribirá:

Todo anda revuelto, todo apriesa, todo marañado. No hallarás hombre con hombre; todos vivimos en asechanza los unos de los otros, como el gato para el ratón o la araña para la culebra, que hallándola descuidada se deja colgar de un hilo y, asiéndola de la cerviz, la aprieta fuertemente, no apartándose della hasta que con su ponzoña la mata (Guzmán de Alfarache, Parte I, Libro II, capítulo IV).

Y no solo el espacio; también el tiempo difumina la acción de los hombres y debilita los acontecimientos que protagoniza, por solemnes o decisivos que hayan sido; hasta los más marcados sucesos históricos pasan ligeros y se olvidan al instante. Sempronio observa cómo el paso del tiempo hace que las cosas humanas se hagan cada vez más borrosas:

Cada día vemos novedades y las oímos y las pasamos y dejamos atrás. Disminúyelas el tiempo, háceles contingibles. ¿Qué tanto te maravillarías, si dijesen: la tierra tembló o otra semejante cosa, que no olvidases luego? Así como: helado está el río, el ciego ve ya, muerto es tu padre, un rayo cayó, ganada es Granada, el Rey entra hoy, el turco es vencido, eclipse hay mañana, la puente es llevada, aquél es ya obispo, a Pedro robaron, Inés se ahorcó, Cristóbal fue borracho. ¿Qué me dirás, sino que a tres días pasados o a la segunda vista, no hay quien de ello se maraville? Todo es así, todo pasa de esta manera, todo se olvida, todo queda atrás (III, 100). 
Es un mundo sin Dios, un mundo regido por relaciones de causas eficientes, mecánicas, sin Providencia; un mundo desconectado del hombre, en el que la vía del amor fraterno, la charitas, ha fracasado, y con él la vía cristiana, el sujeto cristiano. Pero no solo; también la vía judía providencialista defendida en la misma época por Isaac Abravanel (1437-1508), uno de los tres interlocutores de los reyes católicos para conseguir un permiso de residencia para su pueblo por una cantidad razonable de maravedíes. El cosmos, dirá el padre de León Hebreo, es un sistema jerárquico que opera según un plan, y la astrología es el arte de distinguir los hilos ordinarios de este gran tejido cósmico; los hilos extraordinarios quedan fuera de la ciencia, como predecir si un hombre será justo o pecador ${ }^{27}$. Abravanel, como el cristianismo, sigue creyendo en un plan divino que solo por la naturaleza excesiva del ser humano ha introducido el mal en el mundo. Si el cristiano culpa a la soberbia como causa del exceso, Abravanel culpará a la inclinación a lo superfluo, a la insatisfacción con las cosas naturales que Dios había donado al hombre. Pero el resultado es el mismo. En La Celestina ya no hay ninguna esperanza, ni profética ni eclesiástica. La experiencia conversa ni es experiencia cristiana ni es experiencia judía. El mundo está regido por leyes deterministas: «Ninguna cosa hay criada al mundo superflua ni que con acordada razón no proveyesa de ella natura» (VII, 62). $\mathrm{Y}$ esas leyes no tienen ninguna condescendencia para con los hombres; la Naturaleza no está creada a escala humana: «¿Qué me aprovecha a mí me dé doce horas el reloj de hierro, si no las ha dado el del cielo?» (XIV, 250). Las cosas humanas se hacen cada vez más borrosas; incluso la conquista de Granada queda ya olvidada, pues efímera ha sido la victoria de Fernando: «Todo es así, todo pasa de esta manera, todo se olvida, todo queda atrás» (IV, 100). Porque pronto se les olvidó al papado y a los reyes cristianos europeos que la monarquía de Fernando e Isabel pretendía encabezar la «reconquista» de Jerusalén, ad maiorem Christianae gloriam (lo que ha durado más, sin embargo, ha sido la leyenda negra, el despiadado e implacable castigo impuesto por Europa a España a causa de su soberbia: la pretensión de liderar realmente aquella empresa de radio universal fantaseada por los emperadores del Sacro Imperio).

\section{7. «La tragedia de Pleberio»}

Tras páginas y páginas dialogadas, La Celestina concluye con el monólogo angustioso y desesperado de Pleberio. Melibea muere en estricta simetría con Calisto: «Su muerte convida a la mía, convídame y que sea presto, sin dilación; muéstrame que ha de ser despeñada por seguirle en todo» (XX, 292). Pero antes de dejarse caer de la torre abajo, confiesa a su padre el motivo de aquella trágica decisión: el fracaso de la comunicación entre los dos linajes:

${ }_{27}$ B. Netanyahu, Don Isaac Abravanel. Estadista y filósofo, Junta de Castilla y León, Salamanca, 2004. 
Muchos días son pasados, padre mío, que penaba por mi amor un caballero, que se llamaba Calisto, el cual tú bien conociste. Conociste asimismo sus padres y claro linaje; sus virtudes y bondad manifiesta (XX, 291).

Ese «claro linaje» que no pudo ser compatibilizado con el suyo. Pleberio ha de asumir aquella responsabilidad, como padre de familia fracasado, pues ni su esfuerzo ni su búsqueda de «honras» le han servido para vivir en comunidad, para prolongar su estirpe en su hija, condenada desde el principio a vivir su amor en la clandestinidad, fuera de la vista de una sociedad recelosa, una vez destruidas las bases de confianza de las que dependen las relaciones humanas:

¿Para quién edifiqué torres; para quién adquirí honras; para quién planté árboles; para quién fabriqué navíos? (XXI, 294).

Pleberio pide con desesperación que recaiga sobre él mismo toda la desgracia, que tanto recuerda a la que hubo de soportar el bíblico santo Job: «¿Por qué no ejecutaste tu cruel ira, tus mudables ondas, en aquello que a ti es sujeto?; por qué no destruiste mi patrimonio; por qué no quemaste mi morada; por qué no asolaste mis grandes heredamientos?» (XXI, 294). El progressus ejercido desde la Idea de Amor-Gozo no conduce a la vida cristiana, a la charitas, sino a la muerte de Melibea, un suceso más en ese laberinto de errores, en ese desierto espantable, en esa morada de fieras, en ese juego de hombres que juegan a corro, en esa laguna llena de cieno, en esa región llena de espinas, en ese prado lleno de serpientes... que es el mundo de los hombres (XXI, 295). Metáforas terribles de la Tierra en la que se asientan los seres humanos. Porque la muerte de su hija no está engarzada en la lógica militar, ni en la vida biológica que termina con la muerte, ni en los riesgos a que conduce el deseo de aventura o fama. No es la lógica del mundo, sino su principio lo que ha forzado a morir a Melibea: el Amor-Gozo, que, indiferente al mundo, como el Dios nominalista, tiene el poder sobre la vida y la muerte. El único principio ontológico real es el Amor-Gozo: «¿Quién te dio tanto poder», se queja amargamente Pleberio en el Planto del último acto de La Celestina:

¡Oh vida de congojas llena, de miserias acompañada; oh mundo, mundo! Muchos mucho de ti dijeron, muchos en tus cualidades metieron la mano, a diversas cosas por oídas te compararon; yo por triste experiencia lo contaré, como a quien las ventas y compras de tu engañosa feria no prósperamente sucedieron [...] ¡Oh amor, amor, que no pensé que tenías fuerza ni poder de matar a tu sujetos! [...] ¿Quién te dio tanto poder? ¿Quién te puso nombre que no te conviene? Si amor fueses, amarías a tus sirvientes; si los amases, no les darías pena; si alegres viviesen, no se matarían, como agora mi amada hija... (XXI, 295-298). 
El Amor-Gozo está por encima de los diversos estamentos sociales, sean cristianos, gentiles o judíos: Macías, Paris, Elena, Hipermestra, Egisto, Safo, Ariadna, Leandro, David, Salomón o Sansón pagaron con sus vidas su fe en el Gozo. Y fue esa enorme fuerza ontológica del Amor-Gozo la que caló en Melibea y la forzó a morir. El Amor-Gozo no es charitas, es un Amor que destruye por igual individuos y linajes:

Bien pensé que de tus lazos me había librado, cuando los cuarenta años toqué, cuando fui contento con mi conyugal compañera, cuando me vi con el fruto que me cortaste el día de hoy. No pensé que tomabas en los hijos la venganza de los padres (XXI, 297).

No es la Razón, sino el Gozo, enemigo de la Razón, dice Pleberio, el principio ontológico del mundo. Y se queja de ese mundo tan falto de caridad, de comunicación. «¿Por qué — cierra toda la obra Pleberio - me dejaste triste y solo in haec lachrymarum valle?». Pregunta siempre desplazada en la filosofía moderna de cuño cartesiano, y que se revuelve una y otra vez, encajonada por la Razón y la Idea Absoluta, en los desafíos de los libertinos, del marqués de $\operatorname{Sade}^{28}$ o de los sicalípticos. Pleberio ha experimentado en su misma casa la tragedia que envuelve a la condición humana, y ha realizado con la mayor intensidad la vuelta a un mundo regido ahora no por el esfuerzo o por el trabajo, sino por el poder del Gozo. Sabemos que La Celestina ha sido conocida con títulos diferentes: la Comedia de Calisto y Melibea, primero; Tragicomedia de Calisto y Melibea, luego; Libro de Calixto y Melibea y de la puta vieja Celestina, después; finalmente La Celestina, a secas. Mas para la perspectiva filosófica, ¿no sería más apropiado titular la obra La tragedia de Pleberio?

La lectura filosófica nos ha conducido a cambiar, en otra forzosa vuelta de tuerca, el título de la obra. En la synagogué o progressus, hemos recuperado el mundo de partida a través de una Idea, el Amor-Gozo, como condición de posibilidad del mundo, que ya no es solo un sentimiento, sino una idea ontológica. ¿Filosofía o Literatura? La discusión sobre los géneros literarios es tan antigua como la escritura misma, y la separación entre Filosofía y Literatura es recurrente desde el Renacimiento. Ludovico Castelvetro (1505-1571) rechaza en 1570 el diálogo como forma literaria, porque la ficción poética no puede equivaler al discurso moral o ético y, por tanto, filosofía y literatura no deberían mezclarse $^{29}$. Pero podemos recurrir también a nuestros poetas, como Juan de la Cruz,

28 Jacques Lacan ya comprendió que en el reverso de La Razón Pura de Kant se encuentra La Razón Goce de Sade. Cf. J. Lacan, «Kant con Sade», Escritos, II, Siglo XxI, Buenos Aires, 2002, págs. 727-751.

${ }^{29}$ L. Schwartz, «El dialogo en la cultura áurea: de los textos al género», Ínsula, 542, 1992, págs. 1-2 y 27-28. 
que comenta sus poemas desde perspectivas filosóficas. ¿Acaso los comentarios a Subida al monte Carmelo, a Noche oscura del alma o al Cántico espiritual no son espléndidas dilucidaciones ontoteológicas? Habría que estudiar cómo el género ensayístico se impuso en Europa como una expresión más de la formación de las naciones, pero empresa de tal magnitud desborda los límites de este ensayo. En cualquier caso, España, que era un imperio y en el que se pensaba, de acuerdo a su naturaleza, con una perspectiva universal, fue obligada a convertirse en nación tras el triunfo de las naciones: Holanda, Francia, Suecia... Un proceso éste, el del paso de imperio a nación, que aún no ha concluido, y que quizá ya sea imposible concluirlo ${ }^{30}$. Y con demasiada frecuencia, que se ha convertido en hábito, se olvida, tanto individual como institucionalmente, que las grandes aportaciones culturales de España han estado vinculadas al pensamiento universal y no al nacional, como puede comprobarse con la «Escuela Universalista italo-hispánica», sacada a luz prácticamente de las tinieblas por el proyecto de investigación que dirige Aullón de Haro ${ }^{31}$ : las grandes obras de Juan Andrés, Lorenzo Hervás o Antonio Eiximeno y la de multitud de geólogos, botánicos, meteorólogos..., autores de tantas obras que luego han sido utilizadas por franceses, alemanes o norteamericanos, quienes, por cierto, «olvidaron» citar sus fuentes. ¿Cómo no recordar al novohispano Francisco Javier Clavijero (1731-1787), que hubo de responder a la peregrina tesis antropológica de Cornelius de Pauw, seguida por Buffon y por Hegel, que consideraba a América una versión degenerada de Europa? La experiencia conversa hispana o la experiencia universalista hispánica son justamente las experiencias más genuinas del pensamiento ejercido en estas tierras limítrofes y periféricas de aquella Europa Cristiana, despedazada en decenas de naciones que se enfrentaron entre sí en las llamadas Guerras Mundiales del siglo XX, aunque en realidad fueron Guerras Europeas, provocando millones de muertos, la destrucción de ciudades enteras o la horrenda Shoah. Pero esta barbarie europea no le habría sorprendido a Pleberio. Europa no se ha desenredado del poder de la Idea de Amor-Gozo que triunfó sobre la Idea de Amor-Caridad: «Si amor fueses, amarías a tus sirvientes; si los amases, no les darías pena. Si alegres viviesen, no se matarían, como agora mi amada hija» (XXI, 298).

${ }^{30}$ El título del libro de Leandro Prados de la Esclosura es bien explícito: De imperio a nación. Crecimiento y atraso económico en España (1780-1930), Alianza, Madrid, 1993.

${ }^{31}$ Cuyas líneas maestras están recogidas en Pedro Aullón de Haro, La Escuela Universalista Española del siglo XVIII, Sequitur, Madrid, 2016. 